\title{
1. Does everyone feel this way? Loneliness, uncertainty, self-doubts and a distinct lack of time
}

It is lonely running a business, a company, an organization. I feel that the problems I face are unique to me and my company. How could someone else possibly understand my products, my services, my markets, my staff, the issues I face and all the things that make me and my business what we are? After all, I have spent years getting to where I am today.

Even inside my company I feel that I have no one I can openly turn to. I can't talk to those around me as they expect answers from me, not doubts, not questions. They want answers! Indeed, some of the issues that the organization faces have been caused by them. How can I talk to them about problems that I believe they are part of or that they have caused?

Deep down, I know I can't do it all on my own. I try and involve others in running the business but too regularly they let me down and I end up doing the work myself. In any case, it's quicker if I do it myself as it gets done correctly. If not, then I only have myself to blame. Yes, that's the best way to keep things in control, for the time being at least.

Dare I ask myself whether the same managers who have grown up with the business can take the company to the next level? I just don't know. And it is not easy hiring new people either. I've employed "wrong 'uns" before. CVs are all too similar, no one gives poor references and it's difficult to truly see what an individual is like from an interview. Psychometric testing? "That's not for us." Maybe it is best sticking with those that I know well? But plodding on will not bring the success that I want, that I crave, that we deserve. Something will have to change. But what? And how? Let alone in what order!

And where do I get new inputs, insights and innovation from? Effectively I have had to learn on the job. No one has prepared me for the role. There has been no training course and there has been little or no personal development. Leadership does not apply in my firm. It's only for "large" companies. Isn't it? Well, whatever leadership is or is not I am unaware of people who do it well in my circle of friends or business networks. And as for business networks, how can I possibly admit my doubts and concerns to strangers, some of whom may even be competitors? 
Yes, my wits, drive and knowledge of my industry have carried us a long way so far. But as the company grows and we employ more, I have less and less time to spend with customers, with the employees that I have known for years - I simply cannot get around the organization to see what is really going on. Control, it seems, is slipping away like grains of sand between my fingers.

The company has never been as big, I've never run an organization so large and the pace of change is unrelenting. I have doubts on how to grow it further. There are no certainties. My overwhelming feeling is one of isolation leading to more self-doubts draining my already fragile self-confidence. Not that I'll admit that to anyone.

Time. I could do with more of that. I never seem to have enough. I can never really get to do the things I know need to be attended to, the priorities, as I am endlessly consumed by all the urgent things that continually drop on my desk or arrive in my inbox. Business seems to be $24 / 7$, absorbing more and more of my time and energy.

$* * * * *$

Like many business leaders, Freddie Porter, Jane Bishop and Bill Richards felt all of the above. They had no one to turn to despite an ever growing number of business support organizations and consultants offering a confusing battery of similar services.

Freddie, Jane and Bill all ran businesses in the same part of the country and unknowingly had much in common though they had never met. They had survived the recession and despite the difficult trading conditions, all had opportunities to consider.

All three business people had concerns about the performance of their very different companies. Due to various factors, their enthusiasm and confidence were privately waning under their self-doubts. They had no training to lead their respective businesses.

\section{FREDDIE PORTER}

With his dark hair, light stubble beard, permatan and rakish frame, Freddie was a fun-loving and fashionably dressed husband and father of two young children. In his early thirties, the dark sports car parked outside his office reinforced the fast, racy image he liked to portray. Quick-talking Freddie was someone in a hurry, out to prove himself and make his own mark. He frequently used his cheeky smile, the twinkle in his eye and his sheer energy to move things in his direction to get his way. 
As the oldest son, Freddie inherited the century-old family-owned building materials company together with its history and traditions from his recently "retired" father. Freddie worked alongside his two younger brothers but their relationship was a stormy one, not helped by the father who often sided with the brothers. Freddie's wife worked part-time, helping out in the office.

Freddie's father had ruled with an iron fist, controlling all aspects of the business and his sheer will and determination drove the organization. Not only had Freddie inherited the company, he had unknowingly inherited some of his father's rather direct ways though he was trying his best to adopt a more inclusive style. Distributing components to construction companies meant that as a supplier you must always deliver when customers demanded. The task is all-important. Freddie knew that, as did the 82-strong staff. Also, his father, "The Boss", despite being retired, would still come in most days, count the lorries in the yard and make his way to Freddie's office then slate him on the lack of sales, the cleanliness of the wagons or something else that wasn't quite right.

After leaving school, by his own admission, Freddie was not the most confident as he did not enjoy the experience of school. Leaving home, he went to university 90 kilometres away, far enough to be away from home yet near enough to come back when needed. There, he did a sandwich programme which meant he had to spend six months overseas. It was this experience, where he had to stand on his own two feet, that brought him out of his shell. After graduating, he did not join the family firm. Rather, he went to work for another company in the industry, picking up valuable experience of different business practices.

After a few years, an opportunity presented itself to join the family firm as Operations Manager. Freddie did not want to get the job because of his surname. He wanted to obtain the job on merit. He also did not want to be interviewed by his father who was the Managing Director so he went through a robust, three-hour interview with the Financial Director. A short while later, Freddie officially started within the firm. He had no job description, no induction, there would be no personal development, appraisals or direction as to what to do. His first year in the family business was a wasted year.

Nevertheless, Freddie had always looked up to the Financial Director who went on to become Managing Director, moving Freddie into different roles before Freddie became head of the retail division - an opportunity that he was to seize and make a success of. Still, at no stage were objectives agreed with Freddie.

Old business methods and models had remained unchanged over many decades, with personnel and systems left to stagnate. The mentality embedded at management level within the business was one of "the company can run itself, we don't really need director intervention". This 
was probably true to an extent; however, it meant the company would not grow and would progressively worsen over time. With no succession planning, the external accountants and bank managers were increasingly worried about the direction of the business, especially during the recession.

The business had had no one driving it forward and although some of the traditional methods to run a business that were employed were still working, which included relationships built with clients over many years, a good delivery service and good stocks of materials, a severe lack of communication and planning was preventing the company from moving forward.

Eventually the Managing Director retired and Freddie, who had just entered his thirties and become a father for the first time, was appointed to the role of Managing Director with his father as Chairman.

The next generation had arrived.

Freddie knew he had an enormous challenge to turn the company around to be a successful organization.

Again there was no handover. Freddie was full of trepidation, scared of the responsibility. Although it said "Managing Director" on his business card, he did not feel like one. He had the job responsibility but did not know how to do the role. It felt like the blind leading the blind. The management team were not up to standard and the family were all on top of each other, resulting in ill-feeling.

The company had laboured through the last ten years led by an autocratic Board with poor leadership and ineffective communication. The predominant leadership style or management style was autocratic and highly directive. Being told what to do was common. Communication was one-way, top-down. Senior managers felt battered and bruised.

The culture was one of "just do enough to get through" and until Freddie took control, "change" and "succession planning" were words that had never been broached in a generation. It was very challenging for Freddie working with family members on the Board who had very different viewpoints on all manner of ideas and issues surrounding the company. This also had an adverse impact at a personal level on the immediate family members who were not connected to the business.

Freddie knew he had to change "the way we do things around here". In short, he knew he had to change the culture, starting with the leadership style.

\section{JANE BISHOP}

In sharp contrast, bespectacled Jane was the embodiment of a demure, well-spoken and considered business person. Conservatively dressed with 
matching pearl earrings and necklace, Jane's preference for comfortable flat shoes underscored her average height and stature. Trusting, loyal and hard-working and now in her late forties, Jane was Managing Director of a marketing company with a local and regional reach, where she had a small shareholding.

The company was established 35 years ago and during the last two decades it had seen many transformations in the disciplines and services it offers and its ownership - always privately owned by its directors but Board members had come and gone. The company's two major shareholders were accountants and were both involved part-time in the business holding the main financial levers. Jane left the finances to them to manage and accordingly she lacked financial knowledge.

Jane had worked for six years under the owners and was well-liked, but although she knew the technical side of the business inside out and was respected by the staff, the owners did not trust her enough to run the firm unfettered, despite appointing her as Managing Director two years ago.

Jane had made a work-life balance adjustment to join the smaller, independent company as a director. Indeed, she took a pay cut to come aboard as it appeared a stable firm - a blessing after the continual ups and downs in her previous high pressure role. Her long daily commute of over an hour each way had thankfully gone too. She satisfied herself that she would have more time to spend with her husband of two decades and perhaps even write some poetry - a long-held ambition. Jane believed that she had joined an organization where she could influence change, be listened to and feel valued.

That was true for almost four years but at the onset of the recession, the then Managing Director left and the Board asked Jane to take on the role. Whilst being initially excited, Jane had no experience at Board level and she felt she was not equipped to do the job and lead the business out of difficulties.

To survive the downturn, the firm had to cut costs, close a loss-making division, shed overheads, including making staff cuts, and relocate to smaller, more affordable offices. All these things had taken Jane out of her comfort zone but she diligently worked alongside the owners, making the necessary but unpleasant cuts. The Board believed that the business was now in a much stronger position to move forward and be profitable again. The Board thus shifted its focus from fire-fighting and survival to preparation for growth. The company now had ten employees, down from the hundred plus at its zenith two decades ago, and was on the cusp between a micro and a small business.

Having gone through this dramatic change, Jane felt a sense of responsibility to help her company achieve more and release its latent potential to 
deliver success. She believed she needed to be "fully equipped" in order to fulfil that responsibility. Jane had reached the point where she was looking for ideas and for tactics to try, to grow in confidence and to turn these ideas into action in the business that would have a positive impact.

Somewhat poetically, Jane saw her role as one that orchestrated the talents of others towards a common goal and to choose the right score one that made the best of her organization's capabilities and that an audience, the customer, would want to pay to hear. She knew she had to be clear about her expectations and make timely decisions.

However, Jane understood that holding a really good practice session was one thing and recognized that she didn't bring every aspect together to reach the company's performance goals. Inwardly, her confidence as a leader fluctuated wildly and mostly she felt her performance was below par. Typically she would lose herself in the day-to-day tasks and deadlines and then be on the back foot when she realized she had not progressed the more strategic aspects of the business.

Jane did satisfy herself that she was good at building up the confidence of her team but noted she lacked assertiveness, not always following her instincts and then regretting it. Part of Jane felt that she had reached a position of responsibility through "default" - promoted when "someone's got to step in" and where she was the most economic and viable option. While she knew she was supported, she didn't always believe she had earned the right to lead, which of course further undermined her selfconfidence.

Jane had carried the burden of the past for too long: the experience of downsizing, closing operations and making people redundant weighed heavily. This led to a sense of failing despite creating an opportunity for the firm to improve and go forward. But she was ready for a fresh beginning. She had no formal leadership training. She wanted something personal that would address her needs.

Jane reasoned that something had to change if she was going to be able to influence the success of the company as fully as she needed to and wanted to. She didn't feel that she had many great leaders as role models to learn from through her career, so she really wanted to meet others to help guide her. She also needed the time to gain perspective away from daily activities.

\section{BILL RICHARDS}

Lively, energetic and effusive, Bill never seemed to run out of words but he wouldn't waste them either. He was considered, yet prided himself 
in getting straight to the point. Highly self-critical, Bill would continually drive self-improvement. He was a taskmaster, tough on himself and was very hard-working, often taking on what others would be able to do, if he gave them the chance, to ensure things got done to the correct standard.

This all-consuming approach had taken its toll. Now in his mid-forties, he had two broken marriages behind him. He was close to his four children, both emotionally and physically, as they lived nearby, but he did not see them as much as he would have liked. This led to a natural sadness that any parent separated from their children can identify with. He had since had a few relationships but none had lasted for one reason or another. This stoked his fieriness, inflaming his ruddy faced complexion. He was also recovering from a major health scare, an experience he did not want to repeat and one which understandably had set him back.

Bill was an extremely well-dressed, dapper individual, which signalled his colourful character. Dark tailored suits, brightly striped ties and highly polished shoes were his uniform and he wore it well. He would even be spotted wearing spats at formal business evenings. Bill was a confident individual. At two metres tall, muscular and well-built, the fair-haired, blue-eyed Bill had a commanding presence, a natural air of authority with a disarming smile.

Bill ran a professional services company and was one of four equal partners employing 55 staff in three offices in small neighbouring towns in the county. A high street presence was important to the firm as many customers would walk in to seek advice. All three offices had different cultures and an aging workforce. Bill worked at the major office, the most progressive and profitable office, and rarely visited the others. He had other priorities, mostly around workload and meeting clients.

In truth, Bill became Managing Partner as no one else wanted to do it. He was well-liked and respected by his partners. They trusted that he could deliver in the elevated role and acknowledged that he was the best person to do the role.

Bill's natural direct style was diametrically opposite to the machinations of a partnership. He knew he had to listen to his partners, ensuring everyone's thoughts and concerns were heard and considered. But this was very time consuming, and in his profession, time was money. All the partners were specialists working in their own areas and only occasionally came together to discuss the overall direction of the organization. Trying to make decisions for the good of the firm was not easy as everyone had to be consulted. Everyone had an opinion and often these were not always helpful, which slowed progress and frustrated the Managing Partner.

Bill had been with his company for over twenty years. When he joined 
he was given a free hand in his department and he enjoyed the autonomy and self-determination. Essentially he was his own boss and became a partner a few years later before his career drifted for a handful of years. In his early thirties, he stepped up his own performance to become the driving force behind the business. He led on restructuring and succession, then asked to become Managing Partner, knowing that no one else wanted to do the role. Previously, whoever had been the most senior had been given the role by default.

Bill could do things his way now. He saw the writing on the wall for the traditional business model and forecast that the sector would undergo major consolidation. He knew the company needed radical change. It needed to be a business as well as a profession; it needed a modern decision-making process in which he could lead, not consult, and be bold. He saw that he would fill the vacuum of leadership that existed. Bill had a vision for the firm and for his future in that vision. It was now time to take the first steps towards that mental picture.

Bill believed he was the lightning rod for change and certainly he was a force of nature as he set out to grow the business to achieve a critical mass through mergers. Quickly, other businesses would contact him to become part of his expanding organization. Within a few short years the firm doubled in size. The strategy was working. However, Bill's "onedimensional approach" had led him to plateau. He now felt he'd lost his way a little.

By his own admission, his leadership style was mixed. He was good in a crisis, performing well and driving projects towards agreed goals, but on matters that held little interest for him his attention was prone to drift and he would not follow through. Staff morale suffered as a result.

Whilst the mergers had been successful, Bill observed that there was a lack of ambition within the firm amongst partners and staff and that organic growth was not being achieved. This was borne out in the review of management accountants and staff appraisals. Bill believed that there was a lack of leadership at various levels within the firm and that staff were acting within their own comfort zones. He recognized that the lack of key performance indicators, both financial and non-financial, did not help either, compounded by the absence of effective communication up, down and across the organization of any meaningful business information.

Bill knew he had to "find time for me" and to get out of the office. He recognized that he did not have the skills to "take the company to the next level".

Today, Bill found himself gazing into the distance and pondering, "Where do I want to take my business? To what extent am I a significant 
constraint on the growth of the business? Where do the opportunities lie? Where does growth lie for the business?"3

\section{THEORY SANDWICH 1 THE OWNER/MANAGER, LEADERSHIP AND BUSINESS GROWTH}

Here we outline what is understood in terms of how small business growth is interrelated with the owner/manager's leadership aspirations and practices. We show how growth can be stifled by the owner/manager and why leadership development is critical to the survival and growth of small firms.

The ability to learn through gaining and applying new knowledge is of significant importance for enhancing SME performance (Jones et al., 2010). Leadership has been identified as an important factor in the success and failure of SMEs and is crucial to national and regional economies of most developed countries (Anderson, 2002; Thorpe et al., 2009).

The owner/manager is the major influencing factor in determining the culture within an SME (Schein, 1992) and in shaping the way that things are done in an organization. Leadership is strongly argued to be a process of sense-making (Smirich and Morgan, 1982; Pye, 2005). Kempster (2009a) goes further, suggesting leadership is a process of "sense-giving" seeking to shape the sense-making processes of others. Viewing leadership as sense-giving points to leadership as also being an outcome (Drath et al., 2008). Drath et al. (2008) suggest that leadership as an outcome should be considered as a combination of direction, alignment and commitment. In this way an owner/manager is the dominant process of shaping colleagues' sense of the direction the business needs to travel in, how to align efforts and galvanize commitment to the direction and aligned efforts.

SMEs are dependent on the owner/manager's insight, leadership skills, training, education and the background of the company's leader. Often, lack of these characteristics shaping the process of leading is the cause of small business' lack of success (Gaskill et al., 1993), that is, the process of leading is weak and thus direction, alignment and commitment are similarly weak.

Leadership within SMEs has certain challenges. SME owner/managers

${ }^{3}$ These are questions explored at the different stages of a LEAD delegate's journey from before coming on the programme, through the induction and onto LEAD itself. During the ten months of the programme, the questions come mainly from the Masterclasses or are wider leadership development questions. We hope that these questions allow the reader to reflect on their own personal leadership development. 
have very different career aspirations from those in larger organizations and do not typically identify themselves as a leader (Kempster and Watts, 2002). There is general acceptance that social phenomena such as leadership are learnt most notably through the process of observation (Bandura, 1986; Kempster, 2009a) and this is the dominant process of social learning.

In SMEs, the opportunity for owner/managers to observe leadership is reduced as the owner/manager is often alone and isolated or unable to bounce ideas off and confide in their management team, if they have one (Smith and Peters, 2006). Often they are without peers and have limited role models (Perren and Grant, 2001; Smith et al., 1999; Kempster and Cope, 2010) and often have bad bosses (Kempster, 2009a). There is a lack of in-house training, appraisals and development (Kempster and Smith, 2014). The leadership career pathway is restricted in SMEs for owner/ managers and in many ways the SME context stifles leadership learning but this does not mean the owner/manager is not leading - far from it (Kempster and Cope, 2010). Their leadership has a very powerful effect on their employees and the business. The outcome is that owner/managers often draw on early formative experiences, most notably family, education and first jobs. Therefore it is the small business context that is the crucible where owner/managers learn to lead (Bennis and Thomas, 2002). There the relationship between the owner/manager and the business reinforces and arguably limits leadership learning (Kempster and Cope, 2010).

Cope (2003) noted that owner/managers learn from experience "on the job" and that practical learning takes place in reflecting on that experience, concluding that learning and reflective processes are inextricably linked. However, Kempster $(2005,2009 \mathrm{a})$ identified that within the SME context leadership was of significantly low salience. Not that owner/ managers were not leading - far from it: they were providing a very strong form of leadership, but there was a low recognition of the phenomenon of leadership and they had very little desire to study it, form the perspective of their experiences and be challenged in how they were leading. In major part this reflects a limited conscious desire in many owner/managers to aspire to becoming a leader.

Kempster and Cope (2010) showed that there was a striking contrast between employed managers and owner/managers in terms of the salience of leadership and aspirational desire to become a leader. For the employed manager, leadership was a highly valued concept and being seen by others (certainly those more senior who can promote!) as having potential to lead effectively significantly encouraged their attention to becoming better at leading. In contrast, for the owner/manager the everyday pressing demands were the focus of attention. Kempster and Cope showed that few owner/ managers had mechanisms around them to stimulate attention and reflection 
to improving their leadership: they rarely had a superior to perform to, had few opportunities to observe others and fundamentally owner/managers were not switched on to a desire to review how they were leading, its impact, why they led as they did and how to revise their approach to leading.

It has been argued that the entrepreneur's vision, priorities and competencies influence the strategy planning processes and growth of the business (Majumdar, 2008). Although an entrepreneur is not synonymous with owner/manager, the leadership of a small organization undeniably affects its growth potential. The UK Government recognizes the relationship between management proficiency and performance. Bosworth et al. (2002, p.8) state evidence which suggests that one of the fundamental problems holding back the growth of SMEs is a lack of leadership and management capability to drive performance and enable them to succeed. Successive government schemes have focused on SME growth through leadership development support but within the UK there is much to do in this arena as highlighted by Smallbone et al. (2015).

Leadership education programmes provide a significant opportunity to develop owner/managers if the designs focus on an understanding of how owner/managers have learned thus far to lead, the limitations of the SME context to enable learning and then put in place mechanisms that suit such learners. This is the fundamental thinking that shaped the development of LEAD. We sought to address two questions: how can we create a process for leadership learning that builds on the context of an owner/manager and delivers learning directly applicable to the circumstances of the owner/ manager? How can we make sure that such an approach both develops the owner/manager and addresses the needs of the business? What we do know is there is a need to replicate social learning processes.

The latter question is linked to the relationship of leadership and SME growth. In a review of literature on the relationship between start-up, growth and leadership, Cope et al. (2011) showed that team-based startups were more successful in terms of growth than lone owner/managers. This is because team-based structures have a greater variety of talents and networks. Team-based SMEs adopt a broader form of leadership akin to distributed leadership (a useful review of which is in Bolden, 2011). There is a powerful irony in entrepreneurship. The commitments, skills, ambition and insight that drive the establishment of a start-up become a glass ceiling to business growth. The need for decisions, innovations and the exploitation of networks and opportunities to come out from the owner/ manager leads to the lone owner/manager suppressing the distribution of leadership to others to exploit their networks, to be innovative and take local decisions. The necessary entrepreneurial qualities required at startup do not reflect the leadership qualities for growth. 